\title{
Optical Microscopy and SEM Study of Pyrolytic Carbon Deposits from Coke Ovens
}

\author{
R Barranco ${ }^{1 *}$, JW Patrick ${ }^{1}$, C Snape ${ }^{1}$, T Wu$^{1}$, RM Poultney $^{2}$, \\ C Barriocanal ${ }^{3}$, MA Diez ${ }^{3}$ \\ ${ }^{1}$ Nottingham Fuel and Energy Centre, SChEME, University of Nottingham, Nottingham, UK \\ ${ }^{2}$ Corus Research, Development \& Technology, Teesside Technology Centre, Middlesbrough, UK \\ ${ }^{3}$ Instituto Nacional del Carbón, Consejo Superior de Investigaciones Científicas, Oviedo, Spain \\ Email: richelieu.barranco@ nottingham.ac.uk
}

\begin{abstract}
The presence of pyrolytic carbon deposits can cause a number of serious problems in the operation of a coke oven. They can inhibit the flow of gas out of the oven; their removal may cause damage to the refractories and the coke pusher equipment, in particular when the deposition is extensive, and can affect the sealing of the oven so leading to undesirable emissions. Some plants burn off the carbon deposits in an empty oven and this evidently causes loss in productivity and brickwork damage which can lead to environmental problems. There are some uncertainties regarding the formation mechanism and the nature of the pyrolytic carbon found in carbon deposits. The main objective of the investigation was to study the nature and characteristics of pyrolytic carbon deposits in industrial coke ovens, with particular emphasis on the nature of the carbon deposited adjacent to the oven walls. Study of the carbon deposits by optical microscopy and SEM showed a variable concentration of carbon entities as well as differences in packing density. The majority of the deposited carbon was found to be laminar in nature, although the major component initially deposited on the brickwork appeared to be spherulitic. Some degree of gasification of the carbon material in some samples was also apparent.
\end{abstract}

Keywords

Carbonisation, Coke making, Carbon materials

\section{INTRODUCTION}

During the production of coke, evolved volatiles flow alongside the oven walls and into the free space above the charge. Some hydrocarbon components from the volatile are pyrolytically decomposed under the thermal conditions, whereby some of the resulting compounds deposit on the various solid surfaces in the coke oven. Their adhesion to the brickwork can be strong and their reactivity low, so that their removal can be difficult. Some plants burn off the carbon deposits in an empty oven and this obviously causes loss in productivity and brickwork damage, which can lead to environmental problems.

Some attempts to describe and characterise the various pyrolytic carbon forms have been made by various authors (Bokros, 1969; Krebs, 1994; Krebs, 1996; Nakagawa, 1998; Reznik, 2002). However, the terminology and descriptions used are not consistent. Moreover, there are some uncertainties regarding the formation mechanism and the nature of the pyrolytic carbon found in carbon deposits, particularly the layer formed adjacent to the oven walls. The objective of the

\footnotetext{
* Author to whom any corres pondence should be addressed.
} 
present investigation was to study the nature and formation of these carbon deposits in industrial coke ovens, with particular emphasis on the nature of the carbon deposited adjacent to the brickwork.

\section{EXPERIMENTAL}

\section{Characterisation of Carbon Deposits}

Three carbon deposit samples (A, B and C) from the walls of three different ovens from an industrial coke battery were used. The removal of the deposits was done by manual rodding between discharging and recharging of the ovens. The average dimensions of the sheets (length $\times$ width $\times$ thickness, in mm) were $600 \times 300 \times 6,250 \times 150 \times 9$, and $250 \times 120 \times 9.5$, respectively.

Three layers of $400 \mathrm{~mm}^{2}$ parallel to the deposition plane of all the deposits were produced using a diamond cutter. These were then mounted in a liquid epoxy resin to form a block of $30 \mathrm{~mm}$ in diameter. The surface of the blocks was ground using water-resistant silicon carbide papers, and then polished using alumina and colloidal silica suspensions. The optical appearance of the samples was then analysed by polarised light microscopy (PLM).

Blocks of approximately $20 \times 20 \mathrm{~mm}$ where produced for al the carbon deposits and the material adjacent to the wall and that on the deposition side were analysed by means scanning electron microscopy (SEM). A series of SEM micrographs perpendicular to the deposition plane, were also taken along the width of the deposits. The micrographs were then merged together in order to see whether there was any significant difference in morphology or packing density between the various carbon layers during deposition on the oven walls.

\section{Pyrolytic Carbon}

The current terminology for describing microstructures of pyrolytic carbon stems from early PLM observation of growth features. This however, does not meet the requirements for a consistent and clear characterisation of the microstructures. Devising a classification system for carbon deposits is not a simple task. Based on the literature and on the appearance of the sample material under PLM and SEM, two major forms of pyrolytic carbon were identified (see Figure 1). A description of such microstructures is given below.

\section{Laminar Carbon (LC)}

Carbon material of laminar structure exhibits a cone/onion-shaped texture and is anisotropic in nature. Normally fissures in concentric circles appear in cross and longitudinal sections. These are more evident when observed under PLM as exemplified in Figures 1a and b.
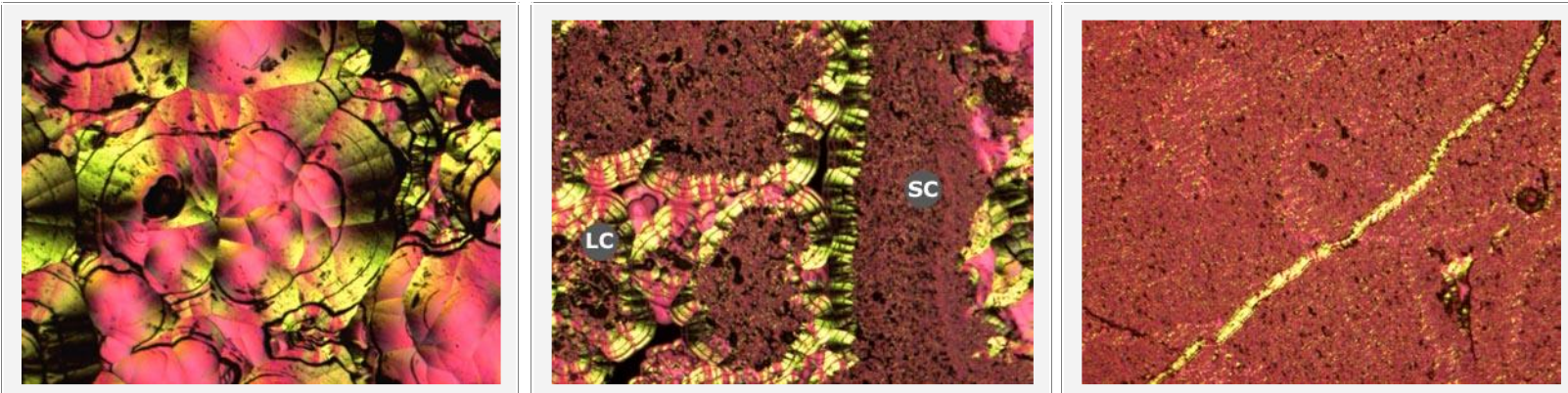
(a) Laminar

(b) Laminar/Spherulitic

(c) Spherulitic

FIGURE 1: Laminar and Spherulitic pyrolytic carbon

Spherulitic Carbon (SC)

Spherulitic carbon material is composed of very small spheres, in some cases of irregular shape, and isotropic in nature (without any growth features and low optical reflectance). The spheres are more easily identified using SEM as shown in Figure 2c.

\section{RESULTS AND DISCUSSION}

\section{Polarised Microscopy Results}

A considerable amount of laminar pyrolytic carbon, which exhibited an onion-shaped texture, was found in all of the three carbon deposit samples, particularly further away from the wall. Spherulitic carbon was also observed but only in samples A and B. This type of carbon tended to be formed near to the wall in sample B, and filling spaces between layers of laminar carbon and pores in sample A. Particles among the pyrolytic carbon were also noticed. Some of them were identified as inertinite particles which might have been carried over with the carbonisation gases, and others as coke or carbonised cenospheres surrounded by pyrolytic carbon. The presence of carbonised coal particles might have resulted from the carbonisation of coal fines deposited in the coke oven during charging. Of all three carbon deposits, sample $\mathrm{C}$ showed a greater concentration of coke, carbonised coal particles and coal fines.

\section{SEM Surface Morphology}

Scanning electron micrographs of the surface of the carbon material on the wall-side of the samples are shown in Figure 2. It can be seen that the majority, if not all, of the material deposited in the brickwork, for samples B and C, appeared to be spherulitic carbon. Laminar carbon was not present on the wall-side of these deposits. For sample A, spherulitic carbon also comprised the majority of the deposited layer, although some laminar carbon could be seen. Nevertheless, it was evident from the surface examination, and by looking at the micrographs, that fracture of the spherulitic layer might have occurred most likely during removal of the deposit from the coke oven. The thickness of the spherulitic carbon layer varies among samples in the order B $>C>>A(400 \mu \mathrm{m}$, $200 \mu \mathrm{m}$, and $80 \mu \mathrm{m}$ respectively). Figure 2 also shows some carbonaceous layers of laminar nature on the interface with the spherulitic carbon layer for all the deposits. 


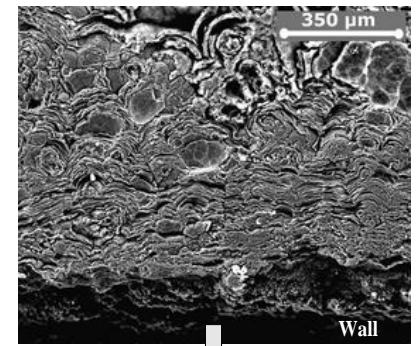

(a) Sample A

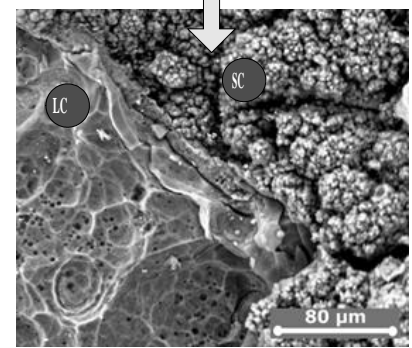

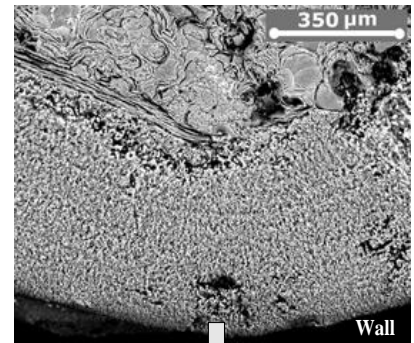

(b) Sample B

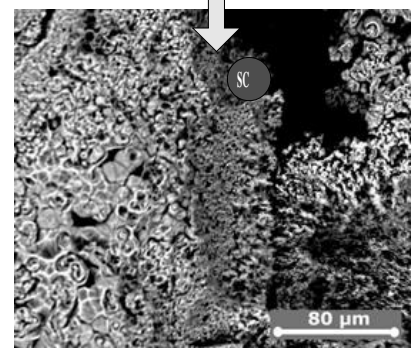

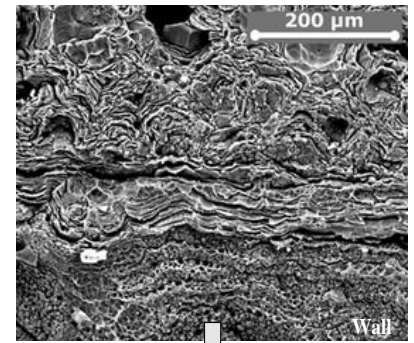

(c) Sample C

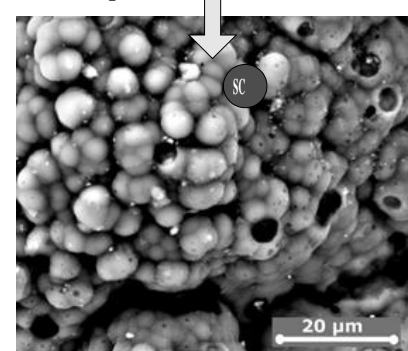

FIGURE 2: SEM micrographs of pyrolytic carbon material from the wall-side of the deposits

Examination of the surface of the carbon material on the deposition side of the deposits showed that laminar carbon was the main component for all the three samples, in agreement with the PLM data. Some degree of gasification of the carbon material on this side of the deposits was apparent. The extent of the gasification of the carbon for samples $\mathrm{C}$ appeared to be more pronounced.

Figure 3 shows the merged SEM micrographs of the material perpendicular to the deposition plane for all three samples. The carbon deposit samples showed some differences in porosity and packing density, being denser towards the deposition side, especially for samples A and B. For sample C, the porosity appears to be concentrated mainly in the middle section of the deposit.

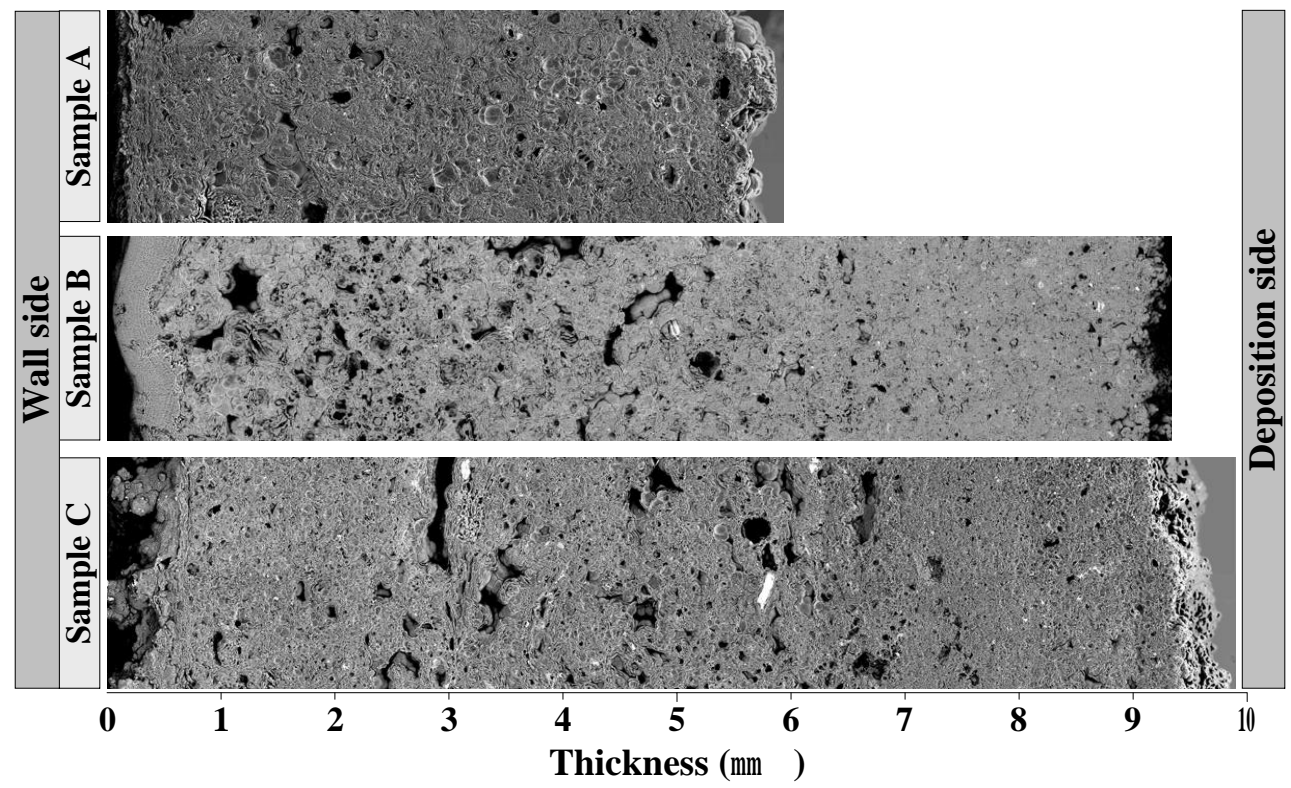

FIGURE 3. Profiles of carbon deposits perpendicular to the wall

\section{CONCLUSIONS}


The carbon deposit samples analysed showed a variable concentration of carbon entities as well as differences in packing density. Although the majority of the deposited carbon was found to be laminar in nature, spherulitic carbon appeared to be the major component initially deposited on the oven walls. Some degree of gasification of the carbon material on the deposition side was also apparent.

\section{Acknowledgements}

The financial support of The European Community through the Research Programme of the Research Fund for Coal and Steel, IMPECABL Project, under contract number RFCR-CT-2004-00004, is greatly acknowledge.

\section{References}

Bokros J C. Deposition, structure and properties of pyrolytic carbon. In: Chemistry and Physics of Carbon, Vol. 5. 1969, New York: Dekker.

Grey R J, and Cathcart J. Nucl Mater, 1966. 19: p. 81-89.

Krebs V, Mareche J-F, Furdin G, and Dumay D. Fuel, 1994. 73(12): p. 1904-1910.

Krebs V, Furdin G, Mareche J, and Dumay D. Fuel, 1996. 75(8): p. 979-986.

Nakagawa T, Suzuki T, Furusawa A, Maeno Y, Komaki I, and Nishikawa K. Fuel, 1998.77 (11): p. 1141-1146.

Reznik B. Carbon, 2002. 40: p. 617-636. 